\title{
PORE PRESSURE RESPONSE OF CLAYEY SEABED UNDER OCEAN WAVE
}

\author{
Yuchen Wang ${ }^{1}$, Erwin $\mathrm{Oh}^{1}$ and Shan-Chun Chang ${ }^{2}$ \\ ${ }^{1}$ Griffith School of Engineering, Griffith University, Australia \\ ${ }^{2} \mathrm{CECI}$ Engineering Consultants, Inc., Taipei, Taiwan.
}

\begin{abstract}
In this study, a 2-D quasi-dynamic u-w-p model is developed to examine the wave-induced clayey seabed behavior. Further, this paper aims to provide a better understanding of the unstable condition of clayey seabed in the vicinity of coastal structure. In the proposed u-w-p model, acceleration, velocity, and displacement terms are considered different for both solid and fluid phases. The governing equations of $\mathrm{u}-\mathrm{w}-$ $\mathrm{p}$ model are determined from constitutive law and conservation law under certain assumptions. The numerical solutions are developed by using Finite Difference Method (FDM) and three outputs (pore water pressure, effective vertical stress and shear stress) are analyzed. The result shows that both liquefaction and shear failure have low potential to occur in clayey seabed, this is due to by the soil structure and low permeability of clay. The pore water pressure vary linearly according to the depth, however, this variation is not significant in clayey seabed. In addition, there is no phase lag in clayey seabed. This paper presents the findings on wave induced stress variation in seabed with fine-grained soil, which differs to some of the published literature on sandy seabed.
\end{abstract}

Keywords: Linear Wave, Clayey Seabed, Shear Failure, Finite Difference

\section{INTRODUCTION}

Wave can potentially damage coastal structures by scouring and causing the stress changes in the foundation soil or seabed. With the wide application of high strength material, the scour damage has already been efficiently reduced [1]. However, the existing methods do not fully reduce damage caused by wave-induced seabed instability. Therefore, considerable efforts have been dedicated to the phenomenon of the wave-seabed-structure interaction ([2], [3], [4], and [5]). As indicated in published literatures, there are two kinds of seabed failures, namely, liquefaction and shear failure. When the pore pressure become excessive with accompanying decrease in effective stresses, a sedimentary bed may be move in either horizontal (liquefaction) or vertical directions (shear failure), then lead to an instability of the seabed [5].

Previous researches have considered seabed stability to a major problem. But, there has been little effort to examine the effects of cyclic bed flow on the effective stress state within the seabed, and the consequences of bed flow with regards to soil stability. In addition, most case studies adopted in previous researches are sandy seabed; therefore not many researches have been conducted with clayey seabed or other types of seabed.

Herein, a u-w-p model (including vertical displacements, horizontal displacements and pore water pressure, denote as "u-w-p") based on quasidynamic condition is established to analyze the transient response of the clayey seabed under wave loading. Finite Difference Method (FDM) is applied to acquire results. In the $\mathrm{u}-\mathrm{w}-\mathrm{p}$ model, acceleration, velocity, and displacement terms are considered different for both solid and fluid phases. This is a complex model and represents the general seabed behavior under wave actions.

In this paper, the behaviors of clayey seabed under wave actions are reported. Numerical models have been developed based on conservation law and constitutive law and linear wave theory. The model is expected to examine the dynamic movement of clayey seabed under different wave conditions. The variation of pore water pressure, liquefaction potential and shear stress will be discussed. With a better understanding of these factors, the seabed failure process could be investigated, and the critical point during the failure process could also be clarified. This will enhance the knowledge of seabed stability, benefit the design of coastal structures, and reduce the potential damage caused by wave.

\section{LITERATURE REVIEW}

In seabed instability analysis, there are two major failure modes. One is shear failure, and another is seabed liquefaction [5]. The shear failure of seabed caused by waves was first forwarded by [1]. Mitchell and Hull [6] followed Henkel's path and substantiated Henkel's findings. Later Wright and Dunham [7] first tried to use finite element method to derive the relationship between wave-induced stresses and seabed displacement. This approach had 
been proved to be effective and applied by many other researchers later. Raham [8] made a comparatively overall summary of mechanisms of wave-induced seabed instability, especially the instability caused by shear stress. Much evidence has been reported in the literature to show that some failures of breakwaters are attributed to foundation failure instead of structural causes [9].

The research of soil liquefaction was first developed in earthquake analysis. In the late 1970s, some scientists recognized that the seabed may have similar phenomena as earthquake liquefaction when strong wave propagated along the seafloor [10]. Wave-induced liquefaction is caused by cyclic loads where the effective stress can reach zero or even smaller than zero under certain circumstance, yet the mechanism of wave-induced liquefaction is quite different from earthquake ([11] and [12]).

Fung [13] had given the solutions for the amplitudes of the harmonic stresses in a semiinfinite elastic medium, with harmonic wave loading on the surface. Demars [14] plotted these stress distributions in dimensionless. In further study of liquefaction, scientists mainly focus on two factors about liquefaction "when' and "where". One is "When the liquefaction may happen?" another is "where or what depth the liquefaction may occur?" As to the first question "when", liquefaction occurs at wave trough phase, at this stage the pore water pressure becomes larger and the effective vertical stress decreases and come to zero [15]. In the loose seabed with relative density around $45 \%$, the soil liquefied to the flume bottom. In the dense seabed with relative density around $60 \%$, the soil liquefied to an intermediate depth. This was also observed by [16] in silt and [17] in sandy bed.

Seabed liquefaction is a major topic in waveinduced soil analysis. Many different approaches have been conducted to find the result, such as using different assumptions (seabed thickness is finite or infinite, saturated or unsaturated seabed, and etc.) or applying different basic theory (Biot consolidation theory or conservation law).

\subsection{Wave-induced Seabed Analysis}

Jeng [18] has made a summary and evaluation of researches about wave-induced soil analysis and wave-induced offshore structure analysis. $\mathrm{He}$ concluded that there were two major research directions in this area, one was the experimental analysis, and another one was theoretical analysis, which included analytical analysis and numerical analysis.

The analytical analysis was first developed based on the Biot's Three Dimensional Consolidation formula [19]. In wave-induced seabed instability analysis, analytical analysis was first developed by [2] and [3], they derived the wave-induced pore pressure, soil displacement and effective stress by direct and skillful mathematic approaches. These analytical solutions were widely used in engineering practice at that time, and it was called YamamotoMadsen Solutions [3]. In addition, Okusa [20] simplified [3] with conditional elastic theory.

Hsu and Jeng [4] developed another important analytical solution. This analytical solution provided a 3-D solution for seabed with infinite depth, and 2D solution for both finite and infinite seabed thickness. This was also the first creditable solution for finite thick seabed. The applied governing equation of this solution was a combination of Three Dimension Biot Consolidation Theory [21] and Storage equation of Verruijt [22]. Hsu and Jeng's [4] solutions had two parts: 3-D solution for finite thickness and 2-D solution for infinite thickness. The 3-D solution still had a room for further refinement, but the 2-D solution for infinite thickness was convinced and practicable [23]. Jeng [5] made further analysis based on the solution developed by [4] and he also made a further study by using numerical analysis. Later Jeng and Seymour [24] extend their analytical solution to different kinds of seabed of both infinite and finite thickness. Further, Jeng [25] assumed that the seabed was cross-anisotropic: the permeability in horizontal direction was different from vertical direction. He concluded if the seabed was assumed to be isotropic, the result had underestimated the effective stresses and overestimated the pore water pressure. He also pointed the importance of permeability in wave-induced seabed analysis again.

In wave-induced seabed study, three major types of numerical analysis methods are applied. They are finite differential analysis, boundary element method, and finite element method. Zen and Yamazaki [26] simplified the problem from 2-dimensional boundary problem into 1-dimensional problem. Jeng [5] has also conducted a series of numerical analysis about wave-induced seabed instability. Jeng [5] has proved the validity of Hsu and Jeng's analytical analysis, and also pointed out the three domain soil parameters in wave-induced seabed analysis. They were permeability, degree of saturation and seabed thickness. The maximum liquefaction depth 
increased when the seabed thickness and permeability decreased, but the maximum failed depth decreased. In addition, the degree of saturation increased, the seabed was easier to be instable. This implied that the liquefaction and shear failure were not consistent under wave-action, not like the wave factors [5]. Later Jeng and Lin [27] extended their numerical model to non-uniform seabed and nonlinear waves. Lin and Jeng [28] made further extension about the numerical model. The model was able to simulate conditions of anisotropic and non-uniform seabed under the wave action.

Recently, several new governing equations have been widely applied. For example, the VolumeAveraged Reynolds-Averaged Navier-stokes (VARANS) equation was adopted as governing equation in [29] and [30].

On the whole, the development of wave-induced seabed analysis has three major stages. The core theoretical framework at the first stage is Yamamoto and Madsen's method [5], this method is simple to apply and suitable to estimate the dynamic stress in industry. Most of the relative researches adopt their research method to conduct further analysis at that time, like [20] and [8]. However Yamamoto and Madsen's method [5] is based on several simplified assumptions, like the seabed is assumed to be infinite thickness, saturated, isotropic and homogeneous. As [25] proved in 1997, these simplified assumptions could affect the final result up to $22 \%$.

Then the research about wave-induced seabed instability comes to the second stage. The most significant finding in this stage is Hsu and Jeng's analytical solution [4]. Jeng ([5], [24] and [25]) has made a lot of numerical studies based on this analytical solution, and extent the results to more complicated seabed conditions, like the seabed could be finite thickness, unsaturated, inhomogeneous and anisotropic. In addition, Jeng also presents a reasonable research methodology. His research begins from analytical solutions, and gets further development through numerical analysis. This is a very clear and logical track. However, Hsu and Jeng's method [4] still has some limitations. It is not so convenient to obtain the seabed soli parameters (elastic modulus, shear modulus, Poisson ratio, permeability and so on) from this method. In general, Hsu and Jeng's method [4] is convinced in describing the seabed behavior under wave actions, but it's not suitable in seabed soil parameter analyses.
In the third stage of wave-induced seabed analysis, the most common work is to develop more accurate numerical models to estimate the result. Most of the research is about the governing equation, like the Volume-Averaged Reynolds-Averaged Navier-stokes (VARANS) equation applied by [30]. Due to the progress in computer application, some complicated governing equations are able to be analyzed now. This may provide better numerical models and highly increase the accuracy of research. This may also be the major research trends in this decade.

\section{GOVERNING EQUATION}

Following assumptions are made in this study:

-Seabed is homogeneous, isotropic and flat surface.

- Linear elastic theory is assumed in all the constitutive models for stress vs. strain relationship.

- Flow behavior is also assumed linear with employing Darcy's Law between hydraulic gradient and pore water flow velocity.

-Sea wave and associated water pressure on seabed surface are given with: Linear wave theory

\subsection{Constitutive Law For Poro-elastic Material}

The constitutive laws for solid phase are expressed based on the linear elastic theory.

(For solid phase)

$\Delta \sigma_{i j}=F \Delta \varepsilon_{k k} \delta_{i j}+2 G \Delta \varepsilon_{i j}$

or $\Delta \varepsilon_{i j}=-F^{\prime} \Delta \sigma_{k k} \delta_{i j}+\frac{\Delta \sigma_{i j}}{2 G}$

Where $\Delta \sigma_{i j}$ and $\Delta \varepsilon_{i j}$ are the stress and strain tensor in i-j plane, respectively. $\delta_{i j}$ is the Kronecker delta, and $\mathrm{G}$ represents the shear modulus.

(For fluid phase)

$$
\begin{aligned}
& (1-n) \Delta \dot{\varepsilon}_{i i}+n \Delta \dot{\varepsilon}_{f i i}=-\left(\Delta \dot{u}_{i, i}+\Delta \dot{w}_{i, i}\right)=\left(\frac{1-n}{K_{s}}+\frac{n}{K_{f}}\right) \Delta \dot{p} \simeq \frac{1}{B_{f}} \Delta \dot{p} ; \\
& B_{f}=\frac{K_{f}}{n}, \frac{1}{K_{f}}=\frac{1}{K_{l}} S_{r}+\frac{1}{K_{g}}\left(1-S_{r}\right), \quad K_{s} \gg K_{f}
\end{aligned}
$$

Where: $B_{f}$ is the average bulk modulus of fluid phase, parameters $\mathrm{K}_{\mathrm{s}}, \mathrm{K}_{\mathrm{f}}, \mathrm{K}_{1}$ and $\mathrm{K}_{\mathrm{g}}$ are the bulk module of solid particles, fluid phase, liquid phase and gas phase, respectively. The bulk modulus of fluid phase $\mathrm{K}_{\mathrm{f}}$ is a function of degree of saturation $\mathrm{Sr}$. and the bulk modulus $\mathrm{K}_{\mathrm{s}}$ of solid particles, which consists of soil minerals, is generally much greater 
than $\mathrm{K}_{\mathrm{f}}$. The parameters with suffix ' $\mathrm{f}$ ' are for those of fluid phase. The newly introduced tensor $\mathrm{w}_{\mathrm{i}}$ is the relative displacement of fluid phase with respective to solid phase; the absolute displacement of fluid is, then, given by Eq. (3), in which $u_{i}$ and $w_{i}$ are the horizontal and vertical displacement respectively. $n$ is the porosity.

(Absolute displacement of fluid phase) $=u_{i}+\frac{w_{i}}{n}$

The relative velocity of pore fluid, or flow of pore fluid, can be described as

$$
\begin{aligned}
& \Delta \dot{w}_{i}=-k_{i j} \Delta h_{, j}=-k_{i j}\left(\frac{\Delta p_{, j}}{\rho_{w} g}-\frac{\rho_{f} \Delta \psi_{i}}{\rho_{w} g}\right)=-\frac{k_{i j}}{\rho_{w} g}\left(\Delta p_{, j}-\rho_{f} \Delta \psi_{i}\right) \\
& r_{i j} \Delta \dot{w}_{j}+\Delta p_{, i}=\rho_{f} \Delta \psi_{i} ; \quad r_{i k} \frac{k_{k j}}{\rho_{w} g}=\delta_{i j}
\end{aligned}
$$

Where $\Delta \dot{w}_{i}$ represents the vertical velocity, $\Delta \psi_{i}$ is the suction, and variable parameter $\mathrm{h}$ is hydraulic potential head, and $\mathrm{k}_{\mathrm{ij}}$ is a tensor for Darcy's permeability law, and the tensor $r_{i j}$ is the inversed form of $\mathrm{k}_{\mathrm{ij}}$. The first term and second term in right part of the equation correspond to pressure head and position head, respectively. For an isotropic permeability, the tensors for permeability become diagonal tensors with uniform components.

$k_{i j}=k \delta_{i j}, \quad r_{i j}=\frac{\rho_{w} g}{k} \delta_{i j}$

Where: $\mathrm{k}$ is a permeability coefficient for ordinary use, based on Darcy's law.

\subsection{Conservation Law For Poro-elastic Material}

The equilibrium condition for overall material including solid phase and fluid phase is derived from Eq. (1); where $\Delta \ddot{u}_{i}$ means horizontal acceleration. $\rho_{t}$ is the bulk density of wet soil, and $\rho_{S}$ is mass density of soil particles and $\rho_{f}$ is bulk density of fluid.

$$
\begin{aligned}
& \rho_{t} \Delta \ddot{u}_{i}+\rho_{f} \Delta \ddot{w}_{i}+\Delta \sigma_{j i, j}+\Delta p_{, i}=\rho_{t} \psi_{i} \\
& \rho_{t} \Delta \ddot{u}_{i}+\rho_{f} \Delta \ddot{w}_{i}-F \Delta u_{j j, i}-G\left(\Delta u_{i, j j}+\Delta u_{j, i j}\right)+\Delta p_{, i}=\rho_{t} \psi_{i}
\end{aligned}
$$

Where total density is

$$
\rho_{t}=(1-n) \rho_{s}+n \rho_{f}
$$

The equilibrium condition for fluid phase is give as the modification of Darcy's permeability law (Eq. (4)).

$$
\rho_{f}\left(\Delta \ddot{u}_{i}+\frac{\Delta \ddot{w}_{, i}}{n}\right)+r_{i j} \Delta \dot{w}_{j}+\Delta p_{, i}=\rho_{f} \Delta \psi_{i}
$$

\subsection{Governing Equations For Poro-elastic Material}

The governing equation is expressed as simultaneous partial differential equations. The acceleration terms are neglected in quasi-dynamic analysis, the 2-D quasi-dynamic u-w-p model can be presented as follows:

[u-w-p] model; quasi-dynamic analysis

$$
\begin{aligned}
& -F \Delta u_{j j, i}-G\left(\Delta u_{i, j j}+\Delta u_{j, i j}\right)+\Delta p_{, i}=\rho_{t} \psi_{i} \\
& r_{i j} \Delta \dot{w}_{j}+\Delta p_{, i}=\rho_{f} \Delta \psi_{i} \\
& B_{f}\left(\Delta \dot{u}_{i, i}+\Delta \dot{w}_{i, i}\right)+\Delta \dot{p}=0
\end{aligned}
$$

This model combined in the governing equation is named as [u-w-p] model. Sometimes the model is simplified according to the appropriate assumptions concerned in the problems. For example, u-w-p model could be simplified into u-p model, where the relative acceleration of fluid phase is neglected; that is, the acceleration of fluid is taken to be equal to that of solid phase. If the effect of pore water flow is negligible as in the problems where the clay ground is concerned under high frequency region or in short term, the seepage flow can be eliminated from the governing equation and the undrained condition can be assumed. In this case the model is called [u]-model; the relative velocity of fluid phase as well as the relative acceleration are neglected. If only the pore water pressure and the pore water flow are concerned, and the deformation of the solid phase is out of the scope of the analysis, the model can be simplified and the solid phase is assumed rigid. This model named [w-p] model is effective for the material with high permeability, such as coarse sand and gravel, and for the static condition. All these models will be presented in future papers, only the most complex and general model (u-w-p model) will be discussed in this paper.

\section{WAVE PARAMETERS AND SOIL PARAMETERS}

Use of parameters in different conditions is shown in table 1; wave parameter and soils 
properties as in table 2 and table 3 . In the problem, the variable parameters, such as displacements, velocity and pressure, are represented by a function.

Displacement $=a(z) e^{i(\omega t+\kappa x)}$

And the function $a(z)$ is solved as a kind of onedimensional problem by finite difference method. The finite difference solution is derived exclusively for two-dimensional dynamic analysis, however, the solution obtained can be easily modified for the other dimensional conditions.

Table 1 Uses of Parameters in Different Conditions

\begin{tabular}{|c|c|c|c|c|}
\hline Condition & $\Delta \ddot{u}_{i}$, & $\Delta \dot{u}_{i}$ & $\Delta \dot{w}_{i}$ & $\Delta \dot{p}$ \\
$\Delta \ddot{w}_{i}$ & & $\Delta \dot{u}_{f i}$ & \\
\hline $\begin{array}{c}\text { Quasi- } \\
\text { dynamic }\end{array}$ & - & + & + & + \\
\hline \multicolumn{4}{|c|}{ "+" considered, “-" = neglected }
\end{tabular}

Table 2 Wave parameters

\begin{tabular}{|c|c|c|c|c|c|}
\hline $\begin{array}{c}\text { Types } \\
\text { of } \\
\text { wave }\end{array}$ & $\begin{array}{c}\mathrm{H} \\
(\mathrm{m})\end{array}$ & $\begin{array}{c}\mathrm{T} \\
(\mathrm{sec})\end{array}$ & $\begin{array}{c}\mathrm{d} \\
(\mathrm{m})\end{array}$ & $\begin{array}{c}\mathrm{L} \\
(\mathrm{m})\end{array}$ & $p_{0}\left(\mathrm{kN} / \mathrm{m}^{2}\right)$ \\
\hline Wave & 10.0 & 13.0 & 20.0 & 167.6 & 37.90 \\
\hline
\end{tabular}

The calculation result of exact solution and numerical solution are also discussed and compared. The mechanical property of normally consolidated clay is listed in Table 3 and the 2-D u-w-p model in quasi-dynamic will be applied to conduct the analysis

\section{FINITE DIFFERENTIAL METHOD (FDM) SOLUTION OF THE MODEL}

This section shows the stress parameters obtained from the governing equation under boundary conditions as shown in Eq. (20). The velocities and displacements in both vertical and horizontal directions have been considered. The pore water pressure and seepage velocity have been applied, too.

$$
\begin{aligned}
& \rho_{t} \frac{\partial^{2} \Delta u_{x}}{\partial t^{2}}+\rho_{f} \frac{\partial \Delta \dot{w}_{x}}{\partial t}-(F+G)\left(\frac{\partial^{2} \Delta u_{x}}{\partial x^{2}}+\frac{\partial^{2} \Delta u_{z}}{\partial z \partial x}\right) \\
& -G\left(\frac{\partial^{2} \Delta u_{x}}{\partial x^{2}}+\frac{\partial^{2} \Delta u_{x}}{\partial z^{2}}\right)+\frac{\partial \Delta p}{\partial x}=0
\end{aligned}
$$

$$
\begin{aligned}
& \rho_{t} \frac{\partial^{2} \Delta u_{z}}{\partial t^{2}}+\rho_{f} \frac{\partial \Delta \dot{w}_{z}}{\partial t} \\
& -(F+G)\left(\frac{\partial^{2} \Delta u_{x}}{\partial x \partial z}+\frac{\partial^{2} \Delta u_{z}}{\partial z^{2}}\right)-G\left(\frac{\partial^{2} \Delta u_{z}}{\partial z^{2}}+\frac{\partial^{2} \Delta u_{z}}{\partial x^{2}}\right)+\frac{\partial \Delta p}{\partial z}=0
\end{aligned}
$$

$$
\begin{aligned}
& \rho_{f}\left(\frac{\partial^{2} \Delta u_{x}}{\partial t^{2}}+\frac{1}{n} \frac{\partial \Delta \dot{w}_{x}}{\partial t}\right)+\frac{\rho_{w} g}{k} \Delta \dot{w}_{x}+\frac{\partial \Delta p}{\partial x}=0 \\
& \rho_{f}\left(\frac{\partial^{2} \Delta u_{z}}{\partial t^{2}}+\frac{1}{n} \frac{\partial \Delta \dot{w}_{z}}{\partial t}\right)+\frac{\rho_{w} g}{k} \Delta \dot{w}_{z}+\frac{\partial \Delta p}{\partial z}=0
\end{aligned}
$$

$$
B_{f}\left(\frac{\partial^{2} \Delta u_{x}}{\partial t \partial x}+\frac{\partial^{2} \Delta u_{z}}{\partial t \partial z}+\frac{\partial \Delta \dot{w}_{x}}{\partial x}+\frac{\partial \Delta \dot{w}_{z}}{\partial z}\right)+\frac{\partial \Delta p}{\partial t}=0
$$

Since the governing equation is a linear simultaneous differential equation with constant coefficients, the fundamental form of the solution becomes:

$$
\left\{\begin{array}{l}
\Delta u_{x}=a_{u x} e^{i \kappa x} e^{i \omega t}, \quad \Delta u_{z}=a_{u z} e^{i \kappa x} e^{i \omega t} \\
\Delta \dot{w}_{x}=a_{w z} e^{i \kappa x} e^{i \omega t}, \\
\Delta p=a_{p} e^{i \kappa x} e^{i \omega t}
\end{array}\right.
$$

These equations are interpreted into finite difference notation and stress parameters are:

$$
\Delta \sigma_{x x}=\left\{-i \kappa(F+2 G) a_{u x(k)}-F \frac{a_{u z(k+1)}-a_{u z(k-1)}}{2 \Delta z}\right\} e^{i \kappa x} e^{i \omega t}
$$

$$
\Delta \sigma_{z z}=\left\{-i \kappa F a_{u x(k)}-(F+2 G) \frac{a_{u z(k+1)}-a_{u z(k-1)}}{2 \Delta z}\right\} e^{i \kappa x} e^{i \omega t}
$$

$$
\Delta \sigma_{z x}=\left(-G \frac{a_{u x(k+1)}-a_{u x(k-1)}}{2 \Delta z}-i \kappa G a_{u z(k)}\right) e^{i \kappa x} e^{i \omega t}
$$

For the response of seabed to sea wave, the following boundary conditions must be satisfied. 
Table 3.3 Mechanical properties of some typical soils selected for the demonstration of frequency dependent wave properties

\begin{tabular}{|c|c|c|}
\hline Material Type & NC Clay & Note \\
\hline$\rho t$ : bulk density of wet material $\left(\mathrm{kg} / \mathrm{m}^{3}\right)$ & $1.80 \times 10^{3}$ & \\
\hline ps: density of solid phase $\left(\mathrm{kg} / \mathrm{m}^{3}\right)$ & $2.75 \times 10^{3}$ & \\
\hline n: porosity & 0.543 & \\
\hline s: shear modulus of solid phase $\left(\mathrm{N} / \mathrm{m}^{2}\right)$ & $0.3 \times 10^{8}$ & \\
\hline vs: Poisson's ratio & 0.30 & \\
\hline B': Skempton's B-value in 1-D & 0.80 & \\
\hline $\mathrm{k}$ : coefficient of permeability $(\mathrm{m} / \mathrm{s})$ & $1.0 \times 10^{-8}$ & \\
\hline e: void ratio & 1.188 & $e=n /(1-n)$ \\
\hline$\lambda \mathrm{s}:$ Lamé's constants $\left(\mathrm{N} / \mathrm{m}^{2}\right)$ & $0.45 \times 10^{8}$ & $\lambda_{s}=2 G_{s} v_{s} /\left(1-2 v_{s}\right)$ \\
\hline Es: Young's modulus of solid phase $\left(\mathrm{N} / \mathrm{m}^{2}\right)$ & $0.78 \times 10^{8}$ & $E_{s}=2\left(1+v_{s}\right) G_{s}$ \\
\hline Eus: stiffness in 1-D of solid phase $\left(\mathrm{N} / \mathrm{m}^{2}\right)$ & $1.05 \times 10^{8}$ & $E_{u s}=2\left(1-v_{s}\right) G_{s} /\left(1-2 v_{s}\right)$ \\
\hline Kf: bulk modulus of fluid phase $\left(\mathrm{N} / \mathrm{m}^{2}\right)$ & $2.28 \times 10^{8}$ & $K_{f}=n E_{u s} B^{\prime} /\left(1-B^{\prime}\right)$ \\
\hline Bf: averaged bulk modulus $\left(\mathrm{N} / \mathrm{m}^{2}\right)$ & $4.20 \times 10^{8}$ & $B_{f}=K_{f} / n$ \\
\hline Sr: degree of saturation of pore $(\%)$ & 99.88 & $S r=\left(1 / K_{a}-1 / K_{f}\right) /\left(1 / K_{a}-1 / K_{w}\right)$ \\
\hline$\rho f:$ bulk density of fluid phase $\left(\mathrm{kg} / \mathrm{m}^{3}\right)$ & $9.988 \times 10^{2}$ & $\rho_{f}=\rho_{a}(1+S r)+\rho_{w} S r$ \\
\hline$\rho d$ : bulk density of dry material $\left(\mathrm{kg} / \mathrm{m}^{3}\right)$ & $1.26 \times 10^{3}$ & $\rho_{d}=(1-n) \rho_{s}$ \\
\hline$\omega 0:$ characteristic angular frequency $(\mathrm{rad} / \mathrm{sec})$ & $5.33 \times 10^{8}$ & $\omega_{o}=n g \rho_{w} / k \rho_{f}$ \\
\hline Maximum B' value & 0.976 & $B^{\prime}=K_{f} /\left(K_{f}+n E_{u s}\right)$ \\
\hline
\end{tabular}

Bulk modulus of saturated water, $\mathrm{Kw}=2.31 \times 109(\mathrm{~N} / \mathrm{m} 2)$

Bulk modulus of air, $\mathrm{Ka}=3.03 \times 105(\mathrm{~N} / \mathrm{m} 2)$

Bulk density of water, $\rho \mathrm{w}=1000.0(\mathrm{~kg} / \mathrm{m} 3)$

Bulk density of air, $\rho a=0.0(\mathrm{~kg} / \mathrm{m} 3$

$$
\begin{array}{ll}
\Delta p(x, 0, t)=p_{o} e^{i(\omega t+\kappa x)}, & z=0 ; \\
\Delta \sigma_{z z}(x, 0, t)=0, & z=0 ; \\
\Delta \sigma_{x z}(x, 0, t)=0, & z=0 ; \\
\Delta \dot{w}_{z}(x, H, t)=-k \frac{\partial \Delta p}{\partial z}(x, H, t)=0, & z=H ; \\
\Delta u_{x}(x, H, t)=0, & z=H ; \\
\Delta u_{z}(x, H, t)=0, & z=H ;
\end{array}
$$

Then

$$
\Delta z=\frac{H}{N}
$$

The boundary conditions at top are interpreted as

$$
\Delta p(x, 0, t)=a_{p(0)} e^{i(\omega t+\kappa x)}=p_{o} e^{i(\omega t+\kappa x)} ; \quad a_{p(0)}=p_{o}
$$

The stress parameters are

$$
\Delta \sigma_{x x}=\left\{-i \kappa(F+2 G) a_{u x(0)}-F \frac{-a_{u z(2)}+4 a_{u z(1)}-3 a_{u z(0)}}{2 \Delta z}\right\} e^{i \kappa x} e^{i \omega t}
$$

$$
\begin{aligned}
& \Delta \sigma_{z z}=\left\{-i \kappa F a_{u x(0)}-(F+2 G) \frac{-a_{u z(2)}+4 a_{u z(1)}-3 a_{u z(0)}}{2 \Delta z}\right\} e^{i \kappa x} e^{i \omega t} \\
& \Delta \sigma_{z x}=\left(-G \frac{-a_{u x(2)}+4 a_{u x(1)}-3 a_{u x(0)}}{2 \Delta z}-i \kappa G a_{u z(0)}\right) e^{i \kappa x} e^{i \omega t}
\end{aligned}
$$


The boundary conditions at bottom are interpreted as

$$
\begin{array}{ll}
\Delta u_{x}(x, H, t)=a_{u x(N)} e^{i \kappa x} e^{i \omega t}=0 ; & a_{u x(N)}=0 \\
\Delta u_{z}(x, H, t)=a_{u z(N)} e^{i \kappa x} e^{i \omega t}=0 ; & a_{u z(N)}=0 \\
\Delta \dot{w}_{z}(x, H, t)=a_{w z(N)} e^{i \kappa x} e^{i \omega t}=0 ; & a_{w z(N)}=0
\end{array}
$$

The stress parameters are

$$
\begin{aligned}
& \Delta \sigma_{x x}=\left\{-i \kappa(F+2 G) a_{u x(N)}-F \frac{3 a_{u z(N)}-4 a_{u z(N-1)}+a_{u z(N-2)}}{2 \Delta z}\right\} e^{i \kappa x} e^{i \omega t} \\
& \Delta \sigma_{z z}=\left\{\begin{array}{l}
-i \kappa F a_{u x(N)} \\
\left.-(F+2 G) \frac{3 a_{u z(N)}-4 a_{u z(N-1)}+a_{u z(N-2)}}{2 \Delta z}\right\} e^{i \kappa x} e^{i \omega t}
\end{array}\right. \\
& \Delta \sigma_{z x}=\left(-G \frac{3 a_{u x(N)}-4 a_{u x(N-1)}+a_{u x(N-2)}}{2 \Delta z}-i \kappa G a_{u z(N)}\right) e^{i \kappa x} e^{i \omega t}
\end{aligned}
$$

\section{GENERAL BEHAVIOUR OF THE SEABED UNDER WAVE ACTION}

The major objective of the study is to identify the effects of different soil parameters in wave-induced seabed instability. To achieve this, it's necessary to clarity the general behavior of the seabed under wave action first. In this section, three main factors are applied to introduce the seabed behavior. They are pore water pressure, effective vertical stress, and shear stress, and the study about soil parameters (like permeability, friction angel, and so on) will be carried out based on these results in further research. A u-w-p model in quasi-dynamic 2-D is employed to introduce the behavior of the clayey seabed in detail.

\subsection{Pore Water Pressure}

The results of pore water pressure variation from the numerical solution are shown in Figure 1 and Figure 2. The pore water pressure decreases with the increase of seabed depth; however, due to the low permeability property of clay, this decrease is relatively small. There is only a $6.2 \%$ decrease in pore water pressure from the seabed surface down to the bottom ( $3 \mathrm{~m}$ deep), and the variation is almost linear. This phenomena is mainly attributed to two factors, the first being the low permeability of clay, which will impede dissipation of pore water; another is the frictional effect between solid and fluid phases in the seabed materials. The frictional effect is taken into account in the analyses and controlled by Darcy's law.

In addition, from Figure 2 it can be seen that pore water pressure of the clayey seabed varies with the wave movement. There is an obvious gap of pore water variation between $Z=0$ (seabed surface) and $\mathrm{Z}=1 \mathrm{~m}$ within the sea bed. The surface soil is not stable and fully consolidated, so it's easy to be washed away by the waves. Therefore the surface layer cannot represent the property of the clayey seabed. Along the depth $(Z=1 \mathrm{~m}$ to $Z=3 \mathrm{~m})$, the pore water pressure does not experience enormous change. The pore water pressure reaches the peak value at $\frac{\pi}{2}$ and $\frac{3 \pi}{2}$, which represent the wave trough and wave crest respectively. One important phenomenon that should be noticed here is that there is no phase lag in the clayey seabed. However, phase lag is very obvious in all sandy seabed studies [5]. As to clayey seabeds, the critical pore water pressure occurs at the trough and crest, instead of a distance form them for sandy seabeds.

uwp model - quasi dynamic - 2D

for normally consolidated clay

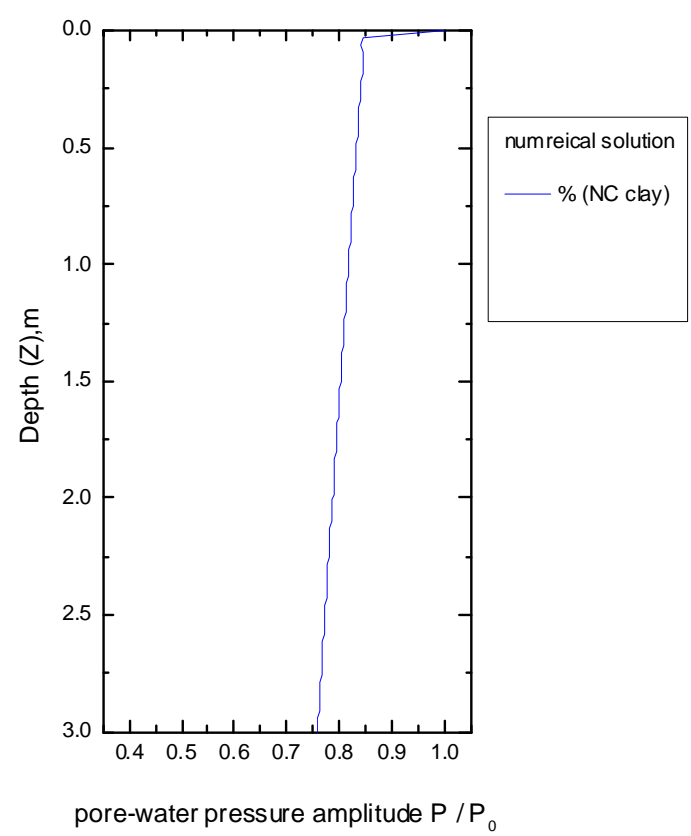

Fig 1 Pore water pressure amplitude in $\mathrm{u}-\mathrm{w}-\mathrm{p}$ model in quasi-dynamic $2 \mathrm{D}$ for normally consolidated clay

\subsection{Effective Vertical Stress}

Effective stress can be calculated as total stress less pore water pressure. The initial stress condition is calculated from the dead weight of the seabed itself and the coefficient of earth pressure at rest, $\left(\mathrm{K}_{\mathrm{o}}\right)$. Cyclic change in effective stress is caused due to cyclic change of the hydraulic gradient. Upward hydraulic gradient which is associated with upward 
seepage flow reduces effective vertical stress and downward hydraulic gradient increases the effective vertical stress. If the upward seepage flow is notable and exceeds a certain value, the effective vertical stress may become negative; this condition is recognized as a kind of liquefaction.

The amplitude of effective vertical stresses increase with depth from 0 to 0.25 shown in Figure 3 . The increase is almost linear, and the growth rate is relatively small. This is caused by the small increase of pore water pressure. It also indicates that stress distribution inside the clay seabed is relatively uniform along the depth. The stress distribution and soil skeleton of the clayey seabed will not have a significant variation with the increase of depth.

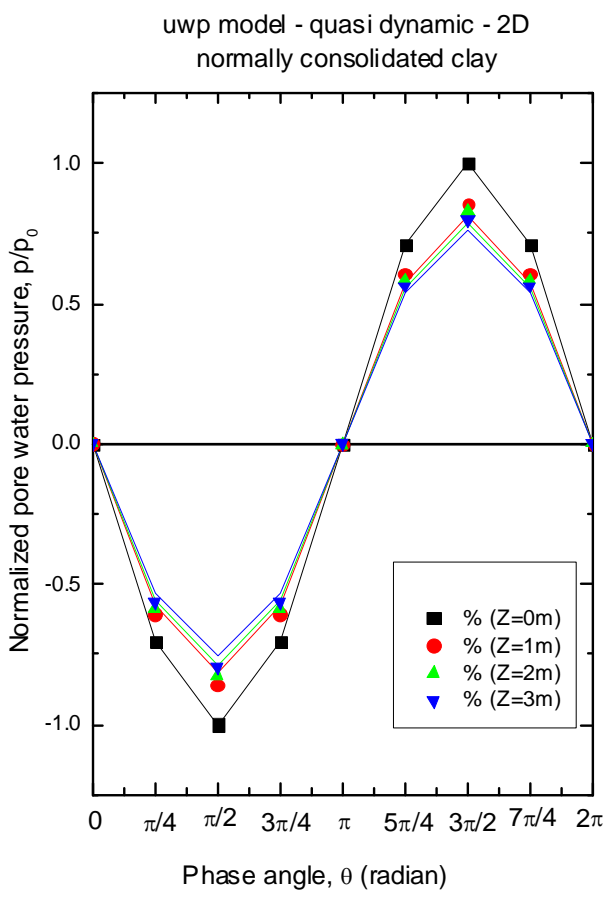

Figure 2 Normalized pore water pressure VS Phase angle in u-w-p model quasi-dynamic 2D for normally consolidated clay.

Cyclic effective vertical stresses, as shown in Figure 4, correspond to the distribution of pore water pressure associated with the friction between pore water and solid skeleton. With an increase of depth, the cyclic effective vertical stress increases in both neutral value and amplitude. Also, cyclic variation of effective vertical stress tends to shift in the same direction as that of wave movement that is the opposite direction of that of pore water pressure. Since the hydraulic flow is downward around the crest of sea waves and upward below the trough of sea waves, z' is high (increases) below the crest and low (decrease) below the trough of the wave.

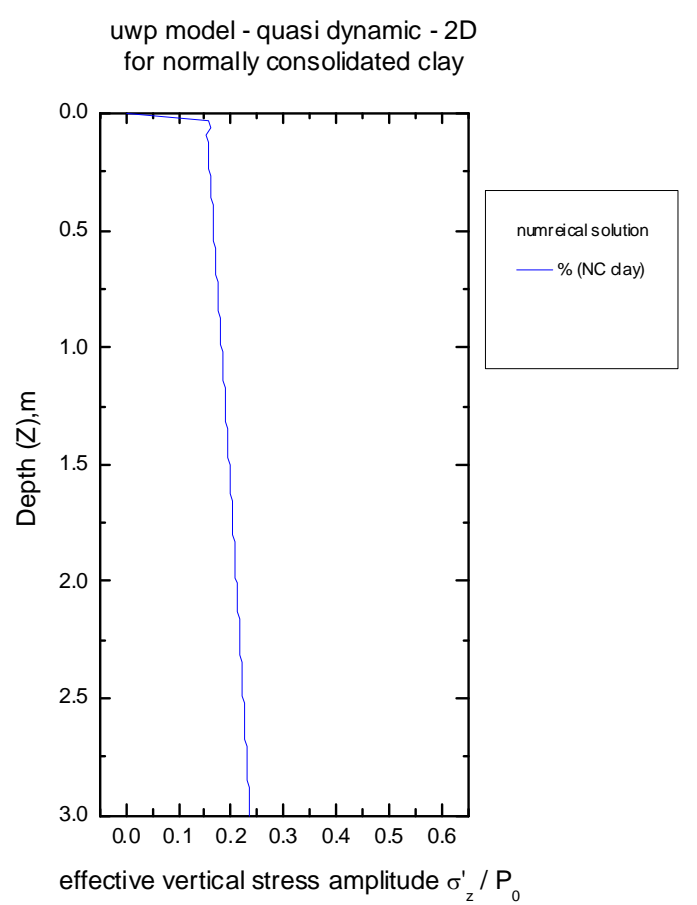

Figure 3 Effective vertical stress amplitude in $u-w-p$ model in quasi-dynamic 2D for normally consolidated clay

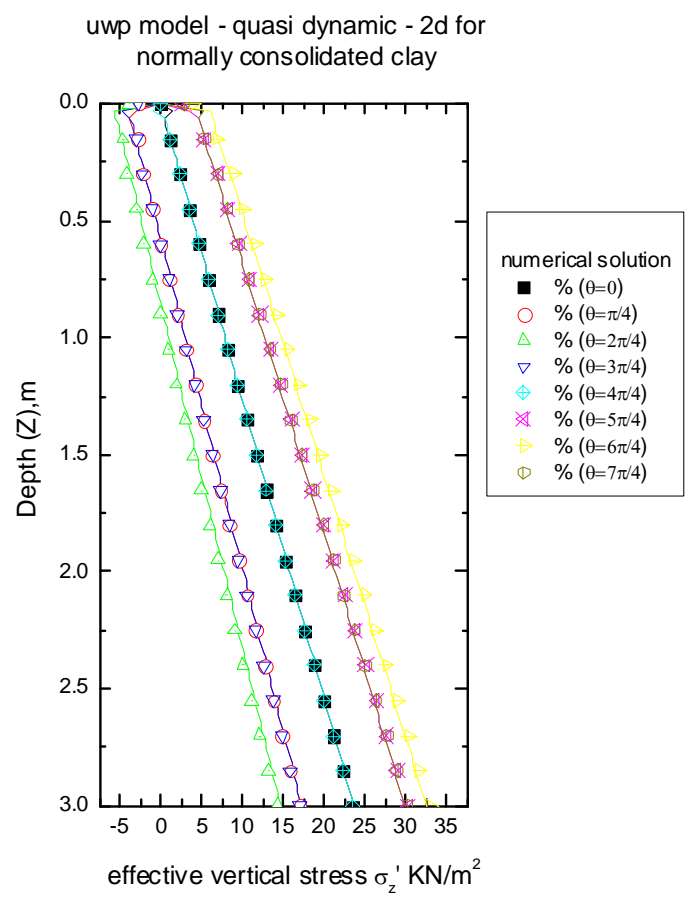

Figure 4 Effective vertical stress in u-w-p model in quasi-dynamic 2D for normally consolidated clay

The effective vertical stress is also an important parameter in determining liquefaction potential of the seabed. The negative value of effective stress occurs when a sea wave is sufficient high. This negative effective vertical stress suggests the occurrence of cyclic liquefaction. The effective 
vertical stress falls into negative only in the surface layer of the seabed $(Z=0 \sim 1 \mathrm{~m})$, as shown in Fig 5 . As mention in the previous section, the surface layer of seabed could not reach a normally consolidated state and the soil particles could be in a suspended state under the influence of buoyancy. There are no liquefactions in deeper layers under these wave conditions. It can be concluded that clayey seabeds have much lower potential for liquefaction to occur. This is determined by the clayey seabed property, in which the dense soil skeleton impedes the increase of excess pore water pressure and also slows the increase of total pore water pressure. The occurrence and intensity of liquefaction is influenced by many factors, such as wave type and material type. In the following research, the influence of the analytical condition and modeling on the cyclic liquefaction will be discussed in detail.

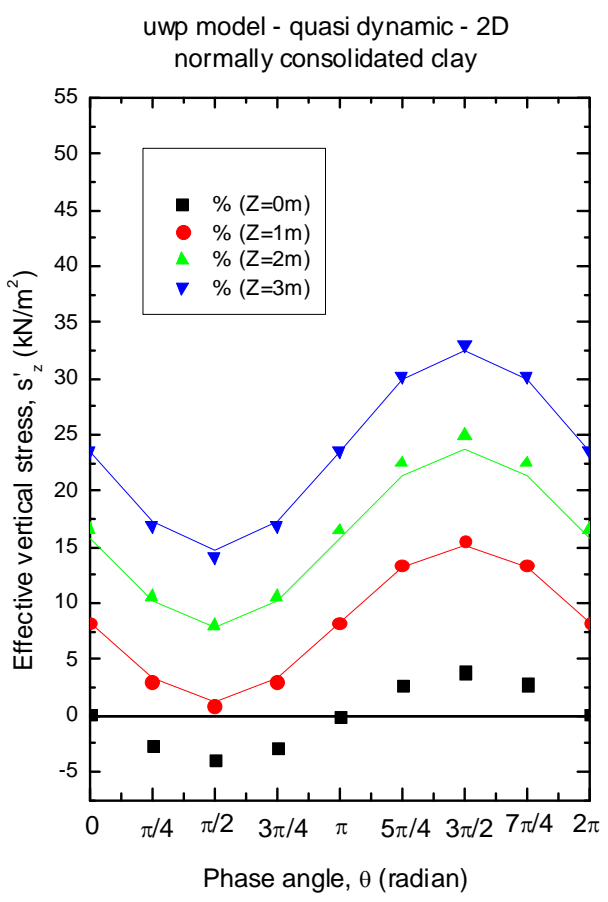

Figure 5 Effective vertical stress VS Phase angle in u-w-p model quasi-dynamic 2D for normally consolidated clay.

\subsection{Shear Stress}

The cyclic shear stress is constantly zero at the surface because the water pressure at the surface is a normal stress, as shown in Figure 6. The phase angle reduces the effect with increasing depth and almost zero at both the phase angles of $\pi / 2$ and $3 \pi / 2$, which correspond to the crest and trough of the sea wave.

This type of cyclic change in shear stress possibly causes the seabed to liquefy and this is named cumulative liquefaction. Pore water pressure may be generated due to the cyclic shear deformation induced by sea wave loading and accumulated after a series of sea wave. The cumulative behavior of pore water pressure is a function of the soil type and cyclic stress conditions. For the prediction of the cumulative generation of pore water pressure and the potential cumulative liquefaction, a nonlinear constitutive model, which can take account of negative dilatancy properties of soils under cyclic loading conditions, must be combined in the appropriate analysis method.

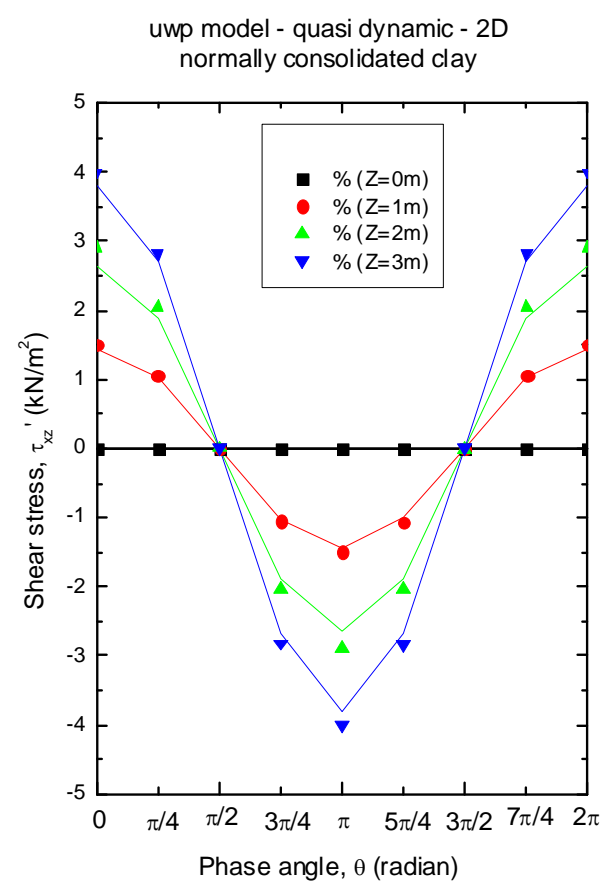

Figure 6 Shear stress VS Phase angle in u-w-p model quasi-dynamic 2D for normally consolidated clay

\section{CONCLUSION}

The numerical method applied in this study provides the means for evaluating the stability of the seabed against sea wave loading. In this paper, the $u-$ $\mathrm{w}-\mathrm{p}$ model under quasi-dynamic condition is mainly presented to simulate the exact seabed behavior under wave action. At this stage of research, the main conclusions drawn are:

-Both the effective stress and the pore water pressure vary linearly according to the depth. However, due to the low permeability of clay, this variation is not significant for clayey seabeds. The pore water pressure only has a $6.4 \%$ difference from the surface $(Z=0 \mathrm{~m})$ to the bottom $(Z=3 \mathrm{~m})$.

-The clayey seabed is unlikely to reach liquefaction, and the most critical effective vertical stress occurs due to the action of wave crests. In addition, there is no phase lag in clayey seabeds. The excess pore water pressure does not accumulate 
quickly and reach a massive value inside the clayey seabeds. Due to its dense soil structure and low permeability, the clayey seabed has relatively low potential of liquefaction.

- The variation of shear stress is almost linear to the wave action, and it's not likely to have shear failure in clayey seabeds.

The following recommendations are planned for future researches on this topic about the study:

- There is a need for experimentation in the laboratory and field to improve understanding of the effects of loading and drainage on natural soil deposits. These results will then be compared with analytical analysis results to modify the models for increasing the accuracy.

- It's necessary to conduct a comparison study among different soil types to better understand the coastal structure failure process created by seabed.

\section{REFERENCES}

[1] Henkel, D. J. (1970). The role of waves in causing submarine landslides. Geotechnique, 20(1), 75-80.

[2] Yamamoto, T. (1977). Wave induced instability in seabeds. In Coastal Sediments (1977) (pp. 898-913). ASCE.

[3] Madsen, O. S. (1978). Wave-induced pore pressures and effective stresses in a porous bed. Geotechnique, 28(4), 377-393

[4] Hsu, J. R. C., \& Jeng, D. S. (1994). Wave - induced soil response in an unsaturated anisotropic seabed of finite thickness. International Journal for Numerical and Analytical Methods in Geomechanics, 18(11), 785-807.

[5] Jeng, D. S., \& Hsu, J. S. C. (1996). Waveinduced soil response in a nearly saturated seabed of finite thickness. Geotechnique, 46(3), 427-440.

[6] Mitchell, R. J., \& Hull, J. A. (1974). Stability and bearing capacity of bottom sedimenets by RJ. Coastal Engineering Proceedings, 1(14).

[7] Wright, S., \& Dunham, R. (1972). Bottom stability under wave induced loading. In Offshore Technology Conference.

[8] Rahman, M. S. (1991). Wave - induced instability of seabed: Mechanism and conditions. Marine Georesources \& Geotechnology, 10(3-4), 277-299.

[9] Silvester, R., \& Hsu, J. R. (1989). Sines revisited. Journal of Waterway, Port, Coastal, and Ocean Engineering, 115(3), 327-343.

[10] Dalrymple, R. W. (1979). Wave - induced liquefaction: a modern example from the Bay of Fundy. Sedimentology, 26(6), 835-844.
[11] Robertson, P. K., \& Wride, C. E. (1998). Evaluating cyclic liquefaction potential using the cone penetration test. Canadian Geotechnical Journal, 35(3), 442-459.

[12] Robertson, P. K. (2009). Interpretation of cone penetration tests-a unified approach. Canadian Geotechnical Journal, 46(11), 1337-1355.

[13]Fung, Y. C. (1965). Foundations of solid mechanics. Prentice Hall.

[14] Demars, K. R., Charles, R. D., \& Richter, J. A. (1980). Geology and geotechnical features of the mid-Atlantic continental shelf. Journal of Petroleum Technology, 32(3), 363-373.

[15] Takahashi, S., Tanimoto, K., \& Shimosako, K. (1994). A proposal of impulsive pressure coefficient for the design of composite breakwaters. In Proc. of the International Conference of Hydro-Technical Engineering for Port and Harbour Construction (pp. 489-504).

[16] Tzang, S. Y. (1998). Unfluidized soil responses of a silty seabed to monochromatic waves. Coastal engineering, 35(4), 283-301.

[17] Tsai, Y. T., Lin, H. C., Yang, M. C. M., Lee, F. Y., Hou, M. C., Chen, L. S., \& Lee, S. D. (1995). Plasma endothelin levels in patients with cirrhosis and their relationships to the severity of cirrhosis and renal function. Journal of hepatology, 23(6), 681-688.

[18] Jeng, D. S. (2003). Wave-induced sea floor dynamics. Applied Mechanics Reviews, 56(4), 407-429.

[19]Biot, M. A. (1956). Theory of propagation of elastic waves in a fluid - saturated porous solid. I. Low - frequency range. The Journal of the Acoustical Society of America, 28, 168.

[20] Okusa, S. (1985). Wave-induced stresses in unsaturated submarine sediments. Geotechnique, 35(4), 517-532.

[21]Biot, M.A. (1941). General theory of threedimensional consolidation. Journal of applied physics, 12(2), 155-164

[22] Verruijt, A. (1969). Elastic storage of aquifers. Flow through porous media, 331-376.

[23] Jeng, D. S. (2001). Mechanism of the waveinduced seabed instability in the vicinity of a breakwater: a review. Ocean Engineering, 28(5), 537-570.

[24] Jeng, D. S., \& Seymour, B. R. (1997). Response in seabed of finite depth with variable permeability. Journal of geotechnical and geoenvironmental engineering, 123(10), 902911.

[25]Jeng, D. S. (1997). Soil response in crossanisotropic seabed due to standing waves. Journal of geotechnical and geoenvironmental engineering, 123(1), 9-19.

[26]Zen, K., Yamazaki, H., \& Sato, Y. (1990). Strength and deformation characteristics of cement treated sands used for premixing 
method. Report of the Port and Harbour Research Institute, 29(2).

[27] Jeng, D. S., \& Lin, Y. S. (1997). NON - LINEAR WAVE - INDUCED RESPONSE OF POROUS SEABED: A FINITE ELEMENT ANALYSIS. International journal for numerical and analytical methods in geomechanics, 21(1), 15-42Smith A. W. S, M. ASCE and Gordon, A. D. (1984)."Large Breakwater Toe Failures." J. Waterway, Port, Coastal, Ocean Eng., 109(2), 253-255

[28]Lin, Y. S., \& Jeng, D. S. (2000). Short-crested wave-induced liquefaction in porous seabed. Journal of geotechnical and geoenvironmental engineering, 126(5), 481-494.

[29]Zhang, J. S., Jeng, D. S., \& Liu, P. F. (2011). Numerical study for waves propagating over a porous seabed around a submerged permeable breakwater: PORO-WSSI II model. Ocean Engineering, 38(7), 954-966
[30]Zhang, C., \& Jeng, D. S. (2013). Numerical Modeling of Seabed Response to Combined Wave-Current Loading. Journal of Offshore Mechanics and Arctic Engineering, 135, 031102-1.

Int. J. of GEOMATE, June, 2014, Vol. 6, No. 2 (Sl. No. 12), pp. 848-858.

MS No. 3198 received on June 15, 2013 and reviewed under GEOMATE publication policies. Copyright (C) 2014, International Journal of GEOMATE. All rights reserved, including the making of copies unless permission is obtained from the copyright proprietors. Pertinent discussion including authors' closure, if any, will be published in the June. 2015 if the discussion is received by Dec. 2014.

Corresponding Author: Yuchen Wang 